\title{
MODELOWANIE HYBRYDOWEGO OBIEGU CHŁODNICZEGO PRZY WYKORZYSTANIU PROGRAMU LABVIEW
}

\begin{abstract}
W Instytucie Inżynierii Cieplnej i Procesowej Politechniki Krakowskiej zaprojektowano i zbudowano prototypowy kaskadowy adsorpcyjno-sprężarkowy system ziębniczy. Pierwszym stopniem kaskady jest urządzenie adsorpcyjne zasilane energią cieplną z kolektorów słonecznych, działające w okresie letnim jako układ chłodniczy, odprowadzający ciepło ze skraplacza drugiego stopnia kaskady sprężarkowego układu ziębniczego z $\mathrm{CO}_{2}$ jako czynnikiem chłodniczym. Do symulacji systemu przygotowany został dedykowany program tworzony z wykorzystaniem graficznego języka programowania w środowisku LabView. Aplikacja uwzględnia jednowymiarowe dynamiczne zmiany parametrów systemu jako całości oraz poszczególnych jego modułów. Rozwiązywane są równania bilansu ilości substancji (masy) oraz bilansu energii. System zawiera cztery typy modułów: a) źródła ciepła i/lub masy, do których należą m. in. kolektor słoneczny, wyparna wieża chłodnicza, komora chłodnicza; b) elementy inercyjne i wymienniki; c) układy napędowe ( $\mathrm{m}$. in. urządzenie adsorpcyjne); d) urządzenia sterujące (np. zawory). W algorytmie obliczeniowym każdy moduł systemu zdefiniowany jest jako podprogram o określonych funkcjach przejścia oraz liczbie wejść i wyjść. Każdy moduł zasadniczo opisany jest przez dwa równania podstawowe - równanie energii i równanie ciągłości - oraz równania uzupełniające, odpowiednie dla poszczególnych elementów systemu. Dla zobrazowania działania programu pokazano przykładowy wykres zmian temperatury wody w zbiorniku jako odpowiedź na skokową zmianę gęstości strumienia promieniowania słonecznego działającego na absorber kolektorów słonecznych.
\end{abstract}

Słowa kluczowe: symulacja jednowymiarowa, bilans energii, kaskada chłodnicza,

\section{Koncepcja systemu adsorpcyjno-sprężarkowego}

Na rysunku 1 pokazano schemat ideowy adsorpcyjno-sprężarkowego urządzenia kaskadowego, którego konstrukcję i zasadę działania szerzej opisano w publikacjach $[1,2]$. Pierwszym stopniem kaskady jest urządzenie adsorpcyjne (3) zasilane energią cieplną z kolektorów słonecznych (1) za pośrednictwem

\footnotetext{
${ }^{1}$ Autor do korespondencji: Ryszard Kantor, Politechnika Krakowska, ul. Warszawska 24, 31-155
} Kraków, 1262835 85, rkantor@mech.pk.edu.pl. 
akumulatora ciepła (2), drugim zaś jest sprężarkowy system ziębniczy oparty na obiegu $\mathrm{CO}_{2}$. Ciepło skraplania czynnika w obiegu drugiego stopnia odbierane jest przez obieg wody zimnej systemu adsorpcyjnego pierwszego stopnia za pośrednictwem wymiennika ciepła (4).

Kolektory słoneczne są głównym źródłem ciepła zasilającego urządzenie adsorpcyjne. Ze względu na ich nierównomierną pracę oraz cykle dobowe i roczne, układ, szczególnie w komercyjnych zastosowaniach, wymaga dodatkowego pomocniczego źródła ciepła, którym może być np. energia odpadowa $\mathrm{z}$ procesów przemysłowych lub ciepło z układów kogeneracyjnych. Istotną zaletą urządzeń adsorpcyjnych jest możliwość alternatywnej pracy, poprzez rekonfigurację układów hydraulicznych z wykorzystaniem najczęściej zaworów trójdrożnych. W okresie letnim mogą pracować jako układy chłodnicze, w okresie zimowym zaś jako układy grzewcze. Urządzenia adsorpcyjne działają wtedy jak pompy ciepła pobierające ciepło $\mathrm{z}$ otoczenia, np. za pośrednictwem wieży wyparnej (5).

Skraplacz $\mathrm{CO}_{2}$ w zimnych okresach roku może być chłodzony powietrzem atmosferycznym, np. z wykorzystaniem wieży wyparnej (5) lub chłodnic wentylatorowych. W takiej konfiguracji urządzenie adsorpcyjne oraz układ solarny mogą działać niezależnie od układu ziębniczego.

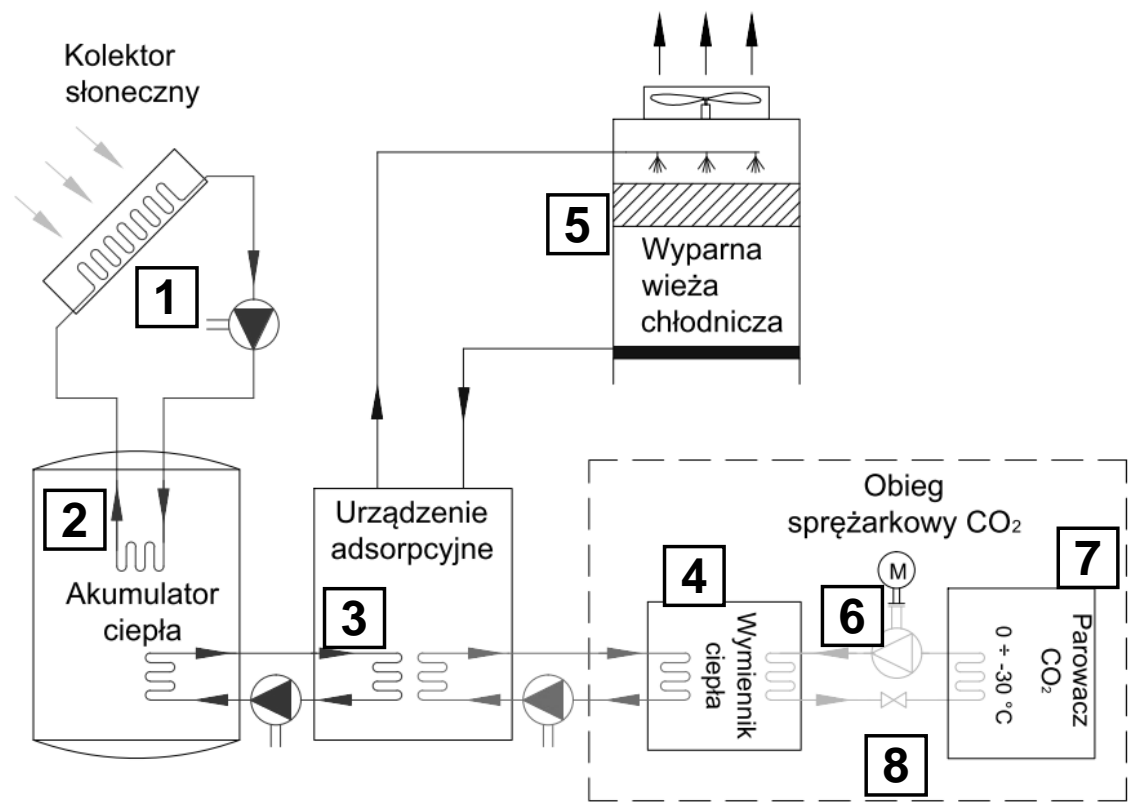

Rys. 1. Schemat systemu: 1 - kolektor słoneczny, 2 - akumulator ciepła, 3 - urządzenie adsorpcyjne, 4 - wymiennik ciepła

Fig. 1. The diagram of the system: 1 - solar collector, 2 - heat accumulator, 3 - adsorption chiller, 4 - heat exchanger 


\section{Modelowanie dynamiczne systemu}

\subsection{Identyfikacja modułów systemu}

Modelowany system zawiera zasadniczo cztery typy modułów:

A - źródła ciepła i/lub masy, do których należą (według rysunku Rys. 1): kolektor słoneczny, wyparna wieża chłodnicza, komora chłodnicza,

B - elementy inercyjne i wymienniki: akumulator ciepła, zbiornik wodny, wymiennik ciepła pomiędzy dolnym i górnym stopniem kaskady.

C - układy napędowe: urządzenie adsorpcyjne, sprężarki,

D - urządzenia sterujące, zawór rozprężny.

W algorytmie obliczeniowym typowy moduł systemu jest zdefiniowany jako programowy blok o określonych funkcjach przejścia i strumieniach wielkości wchodzących i wychodzących z bloku (Rys. 2).

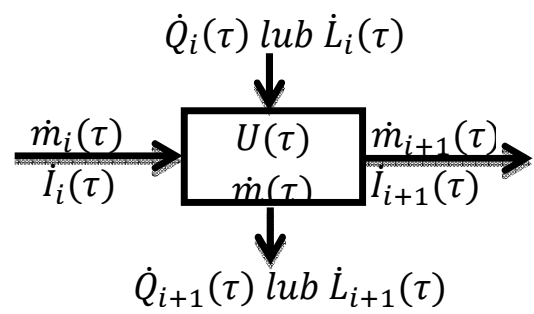

Rys. 2. Pojedynczy typowy moduł algorytmu obliczeniowego

Fig. 2. The single typical module of computational algorithm

Każdy moduł zasadniczo opisany jest przez dwa równania - równanie ciągłości (1) i równanie energii (2). Dla każdej chwili czasowej prawdziwe są równania

$$
\frac{\mathrm{dm}_{\mathrm{i}+1}}{\mathrm{~d} \tau}=\frac{\mathrm{dm}}{\mathrm{d} \tau}+\frac{\mathrm{dm}_{\mathrm{i}}}{\mathrm{d} \tau}
$$

oraz

$$
\frac{d I_{i+1}}{d \tau}+\frac{d Q_{i+1}}{d \tau}\left(\operatorname{lub} \frac{d L_{i+1}}{d \tau}\right)=\frac{d I_{i}}{d \tau}+\frac{d Q_{i}}{d \tau}\left(\operatorname{lub} \frac{d L_{i}}{d \tau}\right)+\frac{d U}{d \tau}
$$

\subsection{Program symulacyjny}

Do symulacji działania systemu przygotowano aplikację zaprogramowaną w środowisku LabWiew [5] (rys. 3). Modelowanie obejmuje większość modułów systemu zdefiniowanych w p. 2.1. 


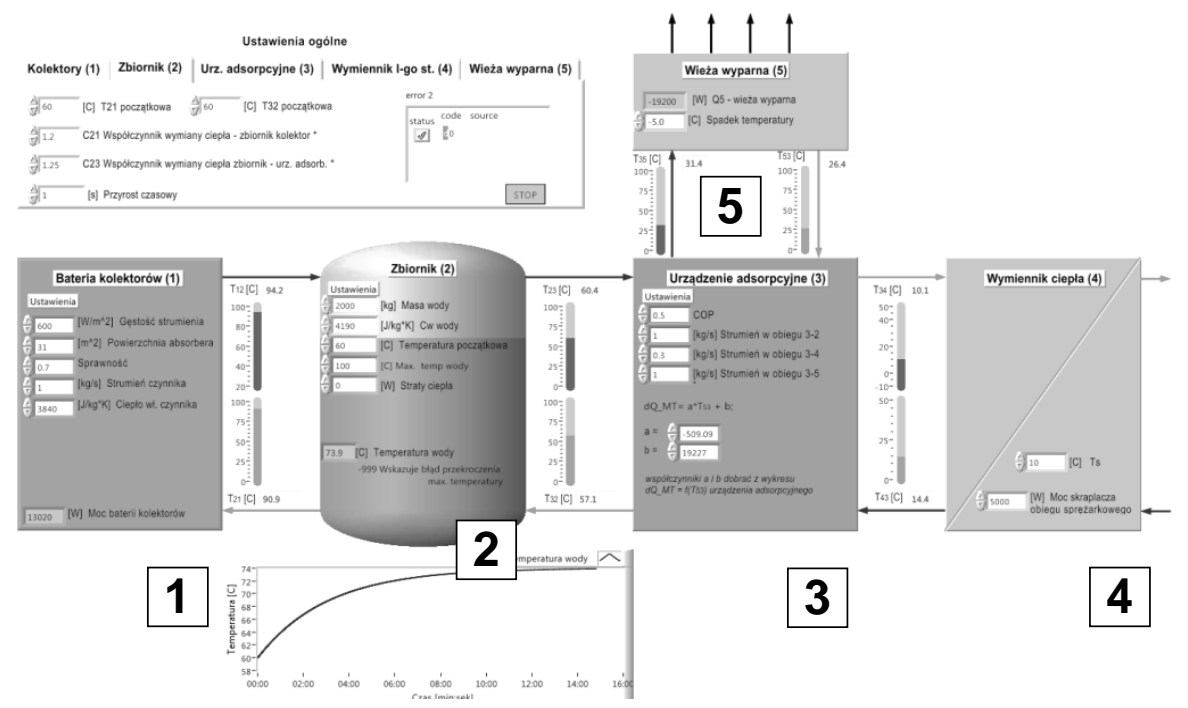

Rys. 3: Panel czołowy programu symulacyjnego

Fig. 3. Front panel of the simulation program

\subsection{Akumulator ciepła - zbiornik (2)}

Format niniejszej publikacji nie pozwala na zaprezentowanie algorytmów obliczeniowych kompletu modułów, stąd bardziej szczegółowo opisano jedynie dwa z nich, kluczowe dla działania systemu. Jednym z nich jest akumulator ciepła - zbiornik (2), którego panel czołowy pokazano na rysunku 4. Zbiornik (2) pełni rolę wymiennika ciepła z możliwością akumulacji ciepła w wodzie. Składa się z dwóch obiegów czynnika grzewczego: obiegu solarnego o strumieniu $\dot{\mathrm{m}}_{1-2}$ oraz obiegu połączonego z górnym źródłem ciepła HT układu adsorpcyjnego o strumieniu $\dot{\mathrm{m}}_{2-3}$. Ciepło przekazywane jest za pośrednictwem cieczy wewnątrz zbiornika, która pełni rolę akumulatora ciepła. Stąd podstawowym równaniem opisującym moduł jest bilans energii:

$$
\dot{\mathrm{I}}_{12}-\dot{\mathrm{I}}_{21}=\dot{\mathrm{I}}_{23}-\dot{\mathrm{I}}_{32}+\frac{\mathrm{dU}}{\mathrm{dt}}+\dot{\mathrm{Q}}_{\mathrm{l}}
$$

gdzie:

$\dot{\mathrm{I}}_{12}$ - entalpia czynnika w obiegu solarnym, na wlocie do zbiornika,

$\dot{\mathrm{I}}_{21}$ - entalpia czynnika w obiegu solarnym, na wlocie do kolektorów,

$\dot{\mathrm{I}}_{23}$ - entalpia czynnika w obiegu z górnym źródłem ciepła HT, na wlocie do zbiornika, 
$\dot{I}_{32}$ - entalpia czynnika w obiegu z górnym źródłem ciepła HT, na wylocie ze zbiornika.

$\frac{\mathrm{dU}}{\mathrm{dt}}$ - zmiana energii wewnętrznej cieczy w zbiorniku,

$\dot{\mathrm{Q}}_{\mathrm{l}}$ - straty energii w zbiorniku.

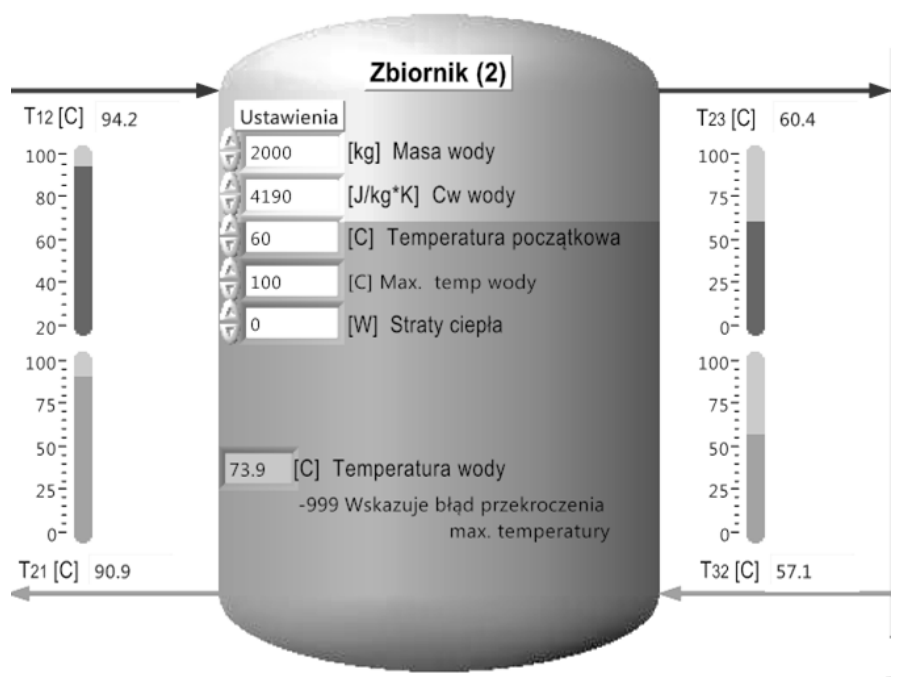

Rys. 4: Panel czołowy modułu akumulatora ciepła - zbiornika (2)

Fig. 4. Front panel of the heat accumulator module of a tank (2)

Dla domknięcia układu równań wykorzystano zależność wymiany ciepła w zbiornikach ogrzewanych cieczą płynącą w wężownicy [3]:

$$
\frac{\mathrm{T}_{\mathrm{w}}-\mathrm{T}_{12}}{\mathrm{~T}_{\mathrm{w}}-\mathrm{T}_{21}}=\mathrm{C}
$$

gdzie:

$$
C=\mathrm{e}^{\frac{\mathrm{k} * \mathrm{~A}}{\mathrm{~m}_{1-2 * C w}}}
$$

$\mathrm{T}_{\mathrm{w}}$ - temperatura cieczy w zbiorniku,

$\mathrm{T}_{12}, \mathrm{~T}_{21}$ - temperatura na wlocie i temperatura na wylocie wężownicy,

$\mathrm{k}$ - współczynnik przenikania ciepła materiału wężownicy,

A - pole powierzchni wężownicy,

$\mathrm{c}_{\mathrm{w}}-$ ciepło właściwe.

Analogiczne równanie wykorzystano dla wymiany ciepła w obiegu HT, co pozwala na domknięcie układu równań w bilansie energii modułu zbiornika (2). 


\subsection{Urządzenie adsorpcyjne (3)}

Drugim istotnym modułem programu jest urządzenie adsorpcyjne (3), którego panel czołowy pokazano na rysunku 5 .

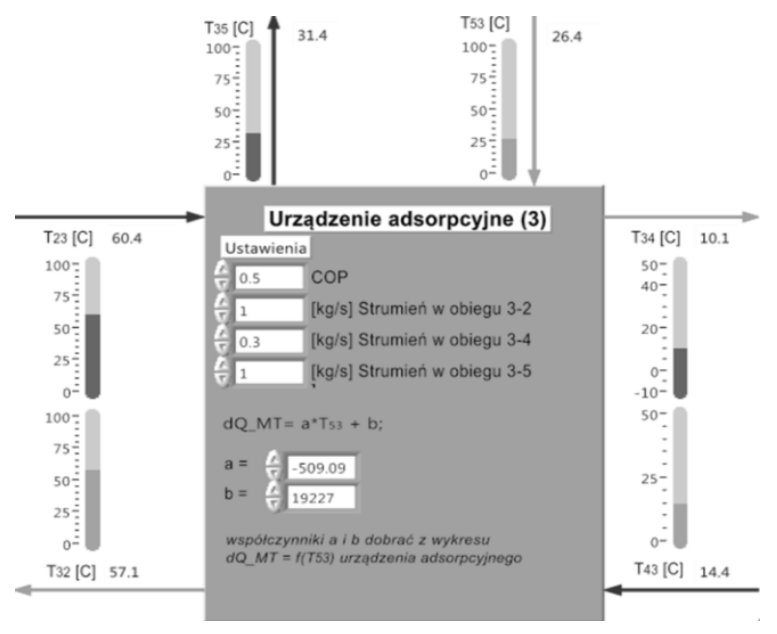

Rys. 5: Panel czołowy modułu urządzenia adsorpcyjnego (3)

Fig. 5. Front panel of the adsorption chiller module (3)

Urządzenie adsorpcyjne zawiera w sobie trzy obiegi cieczy oraz pełni rolę wymiennika ciepła z możliwością akumulacji ciepła. Składa się z trzech obiegów czynnika grzewczego: obiegu LT o strumieniu $\dot{\mathrm{m}}_{3-4}$ połączonego $\mathrm{z}$ wymiennikiem ciepła (4), obiegu HT połączonego ze zbiornikiem (2) o strumieniu $\dot{\mathrm{m}}_{2-3}$ oraz obiegu MT połączonego z wieżą wyparną (5) o strumieniu $\dot{m}_{3-5}$. Ze względu na zróżnicowany i skomplikowany algorytm sterowania pracą urządzenia adsorpcyjnego przyjęto pewne uproszczenia, polegające na możliwości zadania współczynnika COP, strumienia cieczy we wszystkich trzech obiegach urządzenia, przyjęcia modelu modułu jako układu przepływowego a także możliwość skalibrowania funkcji $d Q \_M T=f\left(T_{53}\right)$, stanowiącej równanie uzupełniające. Wartość $d Q \_M T$ jest różnicą entalpii cieczy w obiegu MT. Ze względu na powyższe uwarunkowania podstawowym równaniem opisującym moduł jest bilans energii

$$
\dot{\mathrm{I}}_{23}+\dot{\mathrm{I}}_{53}+\dot{\mathrm{I}}_{43}=\dot{\mathrm{I}}_{32}+\dot{\mathrm{I}}_{35}+\dot{\mathrm{I}}_{34}
$$

Dodatkowe równania domykające układ równań wykorzystują zależności podane przez producenta urządzenia. Pierwsze równanie jest określone przez współczynnik COP dla obiegów sorpcyjnych. 


$$
\mathrm{COP}=\frac{\Delta \dot{\mathrm{I}}_{3-4}}{\Delta \dot{\mathrm{I}}_{3-2}}=\frac{\dot{\mathrm{I}}_{43}-\dot{\mathrm{I}}_{34}}{\dot{\mathrm{I}}_{23}-\dot{\mathrm{I}}_{32}}
$$

Drugim równaniem uzupełniającym jest funkcja $d Q \_M T=f(T 53)$, indywidualna dla każdego urządzenia adsorpcyjnego. Przykładowa funkcja pokazana na wykresie (rys. 6) wykonana jest na podstawie danych producenta [4] urządzenia adsorpcyjnego Sortech ACS 08.

Temp. zasilania $65^{\circ} \mathrm{C}$

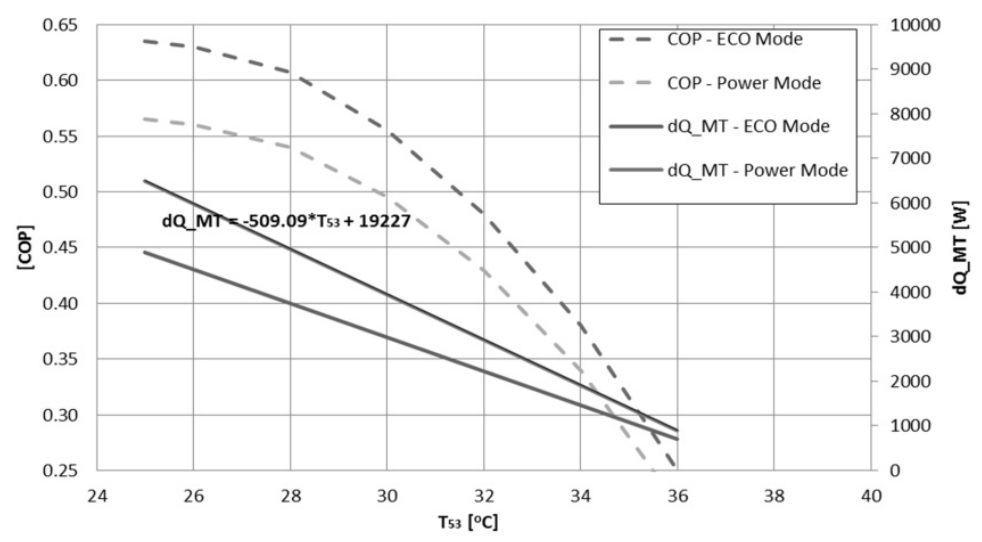

Rys. 6: COP oraz strumień ciepła $d Q \_M T$ w obiegu MT w funkcji temperatury wlotu $T_{53}$

Fig. 6. COP and the heat flux $d Q \_M T$ in MT cycle related to the inlet temperature $T_{53}$

\section{Podsumowanie}

Wykonanie symulacji określonego przypadku wymaga przygotowania i wpisania danych materiałowych i warunków brzegowych dla każdego modułu programu. Program ma możliwość rejestracji zmian temperatury płynu w zbiorniku na wykresie czasowym. Przykładowy wykres wzrostu temperatury w zbiorniku po włączeniu ogrzewania z kolektorów pokazano na rysunku 7.

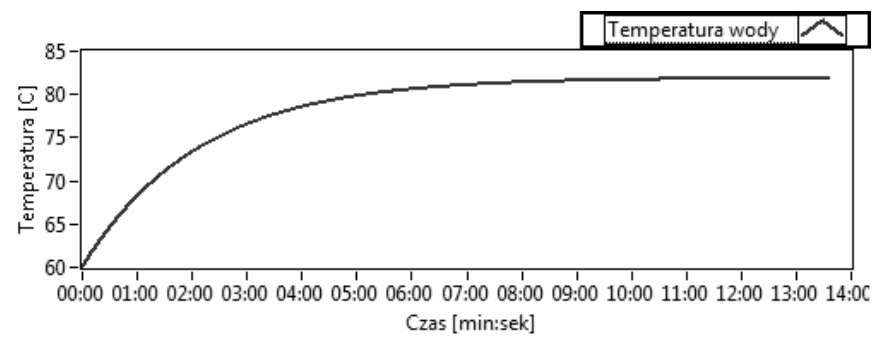

Rys. 7: Wykres zmian w czasie temperatury wody w zbiorniku (2)

Fig. 7. The diagram of the temperature change versus time in the tank (2) 


\title{
Literatura
}

[1] Cyklis P., Górski B., Kantor R., Ryncarz T.: Hybrydowe sorpcyjno-sprężarkowe systemy ziębnicze : Część I - Koncepcja systemu hybrydowego, Technika Chłodnicza Klimatyzacyjna, 19 (2012) 264-268.

[2] Cyklis P., Górski B., Kantor R., Ryncarz T.: Hybrydowe sorpcyjno-sprężarkowe systemy ziębnicze: Część II - Realizacja systemu hybrydowego, Technika Chłodnicza Klimatyzacyjna, 19 (2012) 322-331.

[3] Hobler T.: Ruch ciepła i wymienniki, WNT, Warszawa 1971.

[4] SorTech Adsorption Chiller Design Manual ACS 08/ACS 15.

[5] http://www.ni.com/labview/.

\section{MODELING OF THE HYBRID REFRIGERATION CYCLE BY USING THE LABVIEW PROGRAM}

\begin{abstract}
S u m m a r y
In the Institute of Thermal and Process Engineering at Cracow University of Technology prototype of cascade adsorption-compression refrigeration system has beed designed and assembled. The first stage component of the cascade is the adsorption system feed by the heat generated by the solar collectors, which during summer period work as a refrigeration system rejecting the heat from the condenser of the second stage of compressor refrigeration system with $\mathrm{CO}_{2}$ as the cooling agent. A dedicated program has been made in LabView software environment using the graphic program language. The program is able to simulate one-dimensional dynamic changes of the system parameters as a whole and also its individual modules. The algorithm of the program is based on balance of mass continuity and energy balance equations. The system consists of four types of modules: a) heat and/or mass sources, e.g. solar collectors, cooling towers, cooling chambers b) inertial components and heat exchangers, c) driving systems (e.g. adsorption system), d) control elements (e.g. valves). Each module of the computational algorithm is defined as a numerical sub-program with specified transformation functions and definite number of inputs and outputs. Each module is defined with generally two basic equations of continuity and energy and supplementary equations, appropriate to each module of the system elements. An example of the program operation a diagram of temperature of water in the tank as a response to step change of the flux density of solar radiation acting on the adsorber of solar collectors are presented.
\end{abstract}

Keywords: one-dimensional simulation, energy balance, cooling cascade

DOI: $10.7862 / \mathrm{rm} .2014 .40$

Otrzymano/received: 25.05.2014

Zaakceptowano/accepted: 28.06.2014 